\title{
The Effects of an Alpha-2 Adrenergic Agonist, Guanfacine, on rCBF in Human Cortex in Normal Controls and Subjects with Focal Epilepsy
}

Barbara E. Swartz, M.D., Ph.D., Edward Kovalik, Ken Thomas, Denise Torgersen, and Mark A. Mandelkern, M.D., Ph.D.

Alpha-2 noradrenergic agonists may have wide applicability in the treatment of pre-frontal cortex deficits in primates and behavioral dysfunction in man. We have undertaken this study to determine the effect of an alpha-2 agonist, guanfacine, on regional cerebral blood flow ( $r C B F)$ in humans. Three subject groups were evaluated: normal controls, subjects with frontal lobe epilepsy (FLE), and subjects with temporal lobe epilepsy (TLE). All underwent a number of PET scans using ${ }^{15} \mathrm{O}$-water, with half before and half after a single dose of guanfacine. A wide area of increased $r C B F$ was seen in the frontal lobe, maximal at the central region, following guanfacine in controls and subjects with TLE. Smaller areas of decrease in $r C B F$ were seen in the posterior temporal-occipital cortex. In the FLE group a decrease in $r C B F$ was seen in the dorsal prefrontal cortex on the epileptogenic side with only small increases seen in the mid- to anterior temporal perisylvian areas. The ability of alpha-2 agonists to enhance performance of tasks reliant on prefrontal cortex, without improving tasks believed to rely on intact temporal-hippocampal function, may be explained by these results. Epileptogenic zones appear to create both direct and indirect changes in patterns of drug response. Further studies on the cognitive properties of these agents in humans should be encouraged. [Neuropsychopharmacology 23:263-275, 2000] (C) 2000 American College of Neuropsychopharmacology. Published by Elsevier Science Inc. All rights reserved.
KEY WORDS: Alpha-2 agonists; Adrenergic; Cerebral blood flow; Epilepsy; PET

From the University of California Los Angeles, Neurology Department (BES), Los Angeles, CA; VAMC West Los Angeles, Neurology Service (BES), VAMC West Los Angeles, PET facility (BES, EK, KT, DT, MAM), West Los Angeles, CA; University Cal. Irvine, Physics Department (MAM), Irvine, CA; Case Western Reserve University, Neurology Department (BES) Cleveland, OH.

Address correspondence to: Barbara E Swartz, M.D., Ph.D., University Hospital Health Systems of Cleveland, Neurology Dept., Case Western Reserve U., 11100 Euclid Ave., Hanna House, Cleveland, Ohio 44106-5000, Tel.: 216-844-3714, Fax: 216-844-5066, E-mail: bes5@po.cwru.edu.

Received April 12, 1999; revised February 2, 2000; accepted February $11,2000$.
A growing body of evidence has established that norepinephrine (NE) plays an important role in the performance of cognitive functions in a variety of species (Stein et al. 1975; Oke and Adams 1978; McEntee and Mair 1980; Carli et al. 1983; McGaugh et al. 1984; Leslie et al. 1985). Aged monkeys and young monkeys with either surgical ablations or toxin-induced catecholamine depletion in the prefrontal region (principal sulcus) are unable to perform delayed-response tasks (Bartus et al. 1978; Goldman and Rosvold 1979; Brozoski et al. 1979). Arnsten and colleagues studied rhesus monkeys from 17 to over 30 years in age, and found improved baseline performance on a spatial delayed non-match to sample task following a single dose of the alpha-2 agonist, clonidine (Arnsten and Goldman-Rakic 1985). There were both dose and interval 
(delay) interactions, with greater effects observed as the delay was lengthened. Yohimbine, an alpha-2-antagonist, blocked the effect while neither beta nor alpha-1 antagonists did. A later study showed that guanfacine, an alpha2A agonist, was 10-1000 times more potent than clonidine in this effect (Arnsten et al. 1988).

The alpha-2A adrenergic receptor subtype appears to be the site of action of the beneficial effects of alpha-2 agonists on prefrontal cortex (PFC) function (reviewed in Arnsten et al. 1996; Arnsten 1998). Alpha-2A receptors are localized both pre- and post-synaptically, but several lines of evidence suggest that the site of action is post-synaptic in PFC (Arnsten and Goldman-Rakic 1985; Cai et al. 1993). Their effects on working memory are more pronounced in animals with cell loss or catecholamine depletion, being found at low concentrations in old or depleted monkeys but only at high concentrations in young intact monkeys (Franowicz and Arnsten 1998; Arnsten and Goldman-Rakic 1985 1990; Cai et al. 1993). Stimulation of the locus coeruleus produces a largely inhibitory effect on cortical neurons, whereas a presynaptic action would be expected to produce disinhibition through reduced NE release (Langer 1974). Iontophoresis of the alpha-2 antagonist, yohimbine in monkey PFC neurons suppresses delay-related cellular activity during working memory tasks ( $\mathrm{Li}$ and Kubota 1998; Sawaguchi 1998). Systemic clonidine enhances this delay-related activity, and this enhancement is reversed by iontophoresis of yohimbine in PFC.

Efficacy has also been found with clonidine in an object working memory paradigm, a function believed to rely on ventral prefrontal regions (Jackson and Buccafusco 1991). High doses of guanfacine can improve performance in object reversal tasks, which rely on orbital frontal regions (Steere and Arnsten 1997). Thus both spatial and object recognition working memory tasks are improved by alpha-2-agonists, suggesting a general role for this receptor in working memory. A role in PFC function is reinforced by the findings that infusions of alpha-2 agonists into the PFC improve working memory, while infusions of alpha-2 antagonists into the PFC impair working memory (Li and Mei 1994; Tanilla et al. 1996). Clinical studies of clonidine have reported enhancement of nonspatial abilities in several cognitive disorders (Brozoski et al. 1979; Hunt et al 1985; McEntee and Mair 1980; Mair and McEntee 1986; Fields et al. 1988; Hunt et al. 1995; Chappell et al. 1995; Horrigan and Barnhill 1995).

In contrast to PFC-related tasks, performance of tasks reliant on temporal or parietal lobes is generally unchanged or impaired by alpha-2 agonist treatment (Arnsten and Goldman-Rakic 1985; Arnsten and Goldman-Rakic 1990; Steere and Arnsten 1997; Witte and Marrocco 1997). Instead, the memory functions of the amygdala and hippocampus appear to rely on betaadrenergic mechanisms (McGaugh et al. 1988; Thomas et al. 1996). It is likely that pre-synaptic actions of alpha-2 agonists predominate in these posterior structures, reducing beneficial NE actions at beta-adrenergic receptors.

Norepinephrine (NE) fibers are widely distributed throughout the cortex. They have a common origin in the cells of the locus coeruleus, enter at the frontal poles and arch backward within the gray matter (Morrison et al. 1979; Lewis et al. 1986, 1987). In primates, the cortical distribution of NE and its terminals are highest in the prefrontal cortex and in the primary motor-sensory region (Brown and Goldman 1977). In areas 46, 9, 25, 12 of the frontal cortex, the alpha-2 receptors are prominent in the superficial layers (I, II, and IIIa; Lidow et al. 1989; Goldman-Rakic et al. 1990). These layers are well-suited to cognitive integrative functions as they contain the apical dendrites of layers III and V pyramidal cells, the contralateral callosal and ipsilateral cortico-cortical projections, granule cell dendrite synapses with local circuit neurons, and medial dorsal thalamus projections to pyramidal cells of layers IIIla and $b$. There are at least three structurally different subtypes of alpha- 2 receptors called 2A, 2B, and 2C (Harrison et al. 1991). Our study was not designed to address differences in these subtypes.

In spite of this rich neuroanatomical and neurocognitive literature, few studies have looked at the effects of catecholamines on cerebral blood flow or metabolism. Daniel and colleagues (1991) studied the effects of dextroamphetamine, a non-selective alpha agonist, on rCBF in schizophrenics during the Wisconsin Card Sort test, which is known to rely on intact prefrontal function. No change in rCBF was seen during the task, as compared to a sensorimotor control, prior to the amphetamine, but afterward there was a significant taskinduced increase in rCBF of the left DLPFC. This was accompanied by a significant improvement in performance on the WCST that correlated with the increase in blood flow $(p<.05)$. Moffoot and colleagues showed that clonidine infusion increased $\mathrm{rCBF}$ in the anterior cingulate and PFC of subjects with Korsakoff's syndrome (Moffoot et al. 1994). The increased rCBF in PFC correlated with improvement on verbal fluency, a dominant PFC task. Coull has studied clonidine effects on paired associates and visual information processing tasks using 15O-H2O PET (Coull et al. 1997). In his study, clonidine produced increases in $\mathrm{rCBF}$ in the superior and middle temporal gyri and in the anterior cingulate with decreases seen in the posterior cingulate, cerebellum, thalamus, occipito-temporal and orbitofrontal regions, regardless of task. The clonidineinduced reduction in activity of the thalamus was most prominent during control conditions and was felt to be consistent with an arousal-dependence (low arousal states producing stronger drug effects). The rapid visual-processing task produced increases in the right middle temporal gyrus, which is enhanced by clonidine. Paired associates learning produced a similar increase, but clonidine attenuated this effect. 
We have been interested in working memory function in patients with frontal lobe epilepsy and conducted this study to evaluate if differences in $\mathrm{rCBF}$ would be produced by an alpha- 2 agonist in this group as compared to controls and other focal epilepsies. Specifically, we hypothesized that increased blood flow would be seen bilaterally in the dorsal prefrontal cortex in control subjects following guanfacine, but would not be seen or would only be unilateral in subjects with frontal lobe epilepsy, due to the frontal lesions or epilepsy-induced dysfunction. We also studied the effects in temporal lobe epilepsy subjects who do not typically show deficits in working memory, hypothesizing that they would show a pattern similar to controls, or possibly would show decreases in temporal lobe activity.

\section{METHODS}

\section{Subjects}

Subjects were recruited from patients seen at the West Los Angeles Veteran's Administration Medical Center or from the California Comprehensive Epilepsy Program. Controls were recruited by local advertisement. All controls and patients signed an IRB-approved consent prior to testing. The control subjects were screened to exclude a previous history of loss of consciousness, drug abuse, psychiatric or affective disorder, and were not taking other medications. The epilepsy subjects had a battery of tests to document the seizure focus including neurological history and exam, interictal EEG, ictal video-EEG, neuropsychological tests, MRI, and ${ }^{18}$ FDG-PET (Table 1). Other tests performed in some included magnetoencephalography, intracarotid amytal test (WADA test), and intracranial EEG with or without video. The final decision as to the localization of epileptogenic zones was made by a group of three epileptologists, board-certified in electroencephalography, neuropsychologists and neurosurgeons specializing in seizure localization as described in previous publications (Delgado-Escueta and Walsh 1985; Walsh and Delgado-Escueta 1984; Swartz and DelgadoEscueta 1987; Swartz et al. 1991; Swartz et al. 1998). The decision was made for clinical purposes prior to the inclusion of subjects in this study. Subjects had to be seizurefree for 24 hours prior to scanning and subjects with large structural lesions $\left(>2.5 \times 2.5 \mathrm{~cm}^{2}\right)$ on MRI scans were excluded post hoc because of difficulty with aligning the data to the SPM template and because of the potential confounding effects of lesions on the statistical analyses.

\section{Scans}

Scans were performed on a Siemens 953-31 scanner, which produces 31 contiguous transaxial tomographic images at $3.5 \mathrm{~mm}$ intervals for an axial field of view of $10.8 \mathrm{~cm}$. This results in an image of the brain with a small amount of the vertex sacrificed. The transaxial and in-plane resolutions of the scanner are both approximately $5.6 \mathrm{~mm}$ FWHM. A short rectilinear transmission scan for positioning of the brain prior to the study was performed using a ${ }^{68} \mathrm{Ge}$ external source. Laser cross-hairs were aligned with the nasion, and the transaxial plane of the head was set parallel to the anterior to posterior commisure (AC-PC) line. The head was held in place with a leather head holder and realigned between scans as needed. The attenuation correction of the images is performed by a computation in which the acquired sinograms are employed for definition of geometry of the head. A series of scans using 20-25 mCi ${ }^{15} \mathrm{O}-\mathrm{H}_{2} \mathrm{O}$ are made prior to and beginning at 45 minutes after the ingestion of 2-3 mg guanfacine hydrochloride (Tenex). Each scan period was two minutes with an interscan interval of at least 10 minutes. Due to cyclotron delays the interscan interval is sometimes longer. As a result, the post-drug scans occurred between $45 \mathrm{~min}-$ utes and 2 hours 30 minutes after drug ingestion.

During the scans all subjects in the control, TLE, and FLE groups performed a delayed or immediate matchto-sample task as previously described (Swartz et al. 1994, 1995, 1996a, 1996b). Abstract, non-verbal, images are displayed for $500 \mathrm{msec}$ with an interstimulus interval (ISI) of $250 \mathrm{msec}$ for the IMS task and 8-14 msec for the DMS task. The duration of ISI is varied across subjects to maintain a performance criteria of $75 \%-90 \%$ at baseline. The tasks and scans are balanced pre- and post-guanfacine. The use of a controlled tasks rather than studying drug effects at a "random rest" state helps to remove the confounding influence of uncontrolled cognitive states or states of arousal. The subjects performed 30 repetitions of the task(s) during each scan period. Thus, in this analysis we are looking at the main effect of drug on rCBF in different groups. An additional five subjects were studied with scans pre- and post-guanfacine, but without a task. They are called the "rest control" group.

The scan numbers ranged from 6 to 12, with half preand half post-guanfacine. Approximately one-third of subjects had their scan orders reversed, requiring that the post and pre-drug scans be done on different days. All subject scans were realigned using co-registration to the mean scan of that day rather than of that subject, to account for the two-day confound. Using AIR, all scans are oriented such that the epileptogenic zones would be in the left temporal lobe or the left frontal lobe in the epilepsy subjects (Woods et al. 1992). That is, prior to statistical analysis, all scans of subjects with right-sided foci are reflected 180 degrees in the mid-sagital plane so the abnormalities would align on the left.

\section{Guanfacine Variables}

Blood pressure measurements are made prior to and 1.5 hours after ingestion of the drug. The dose, 2-3 mg, 


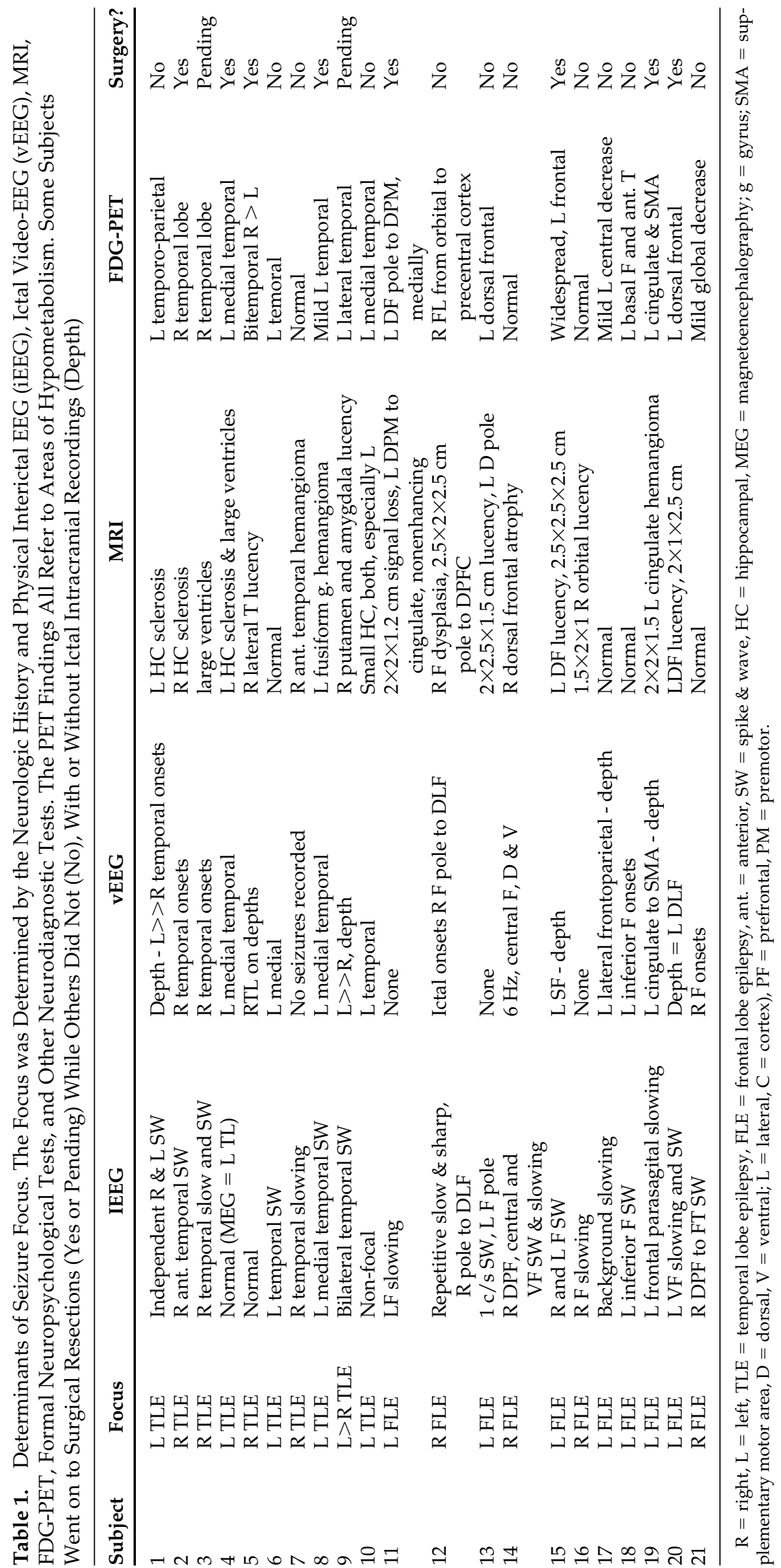


Table 2a. Subject Characteristics. The Age (Range), Sex $(M=$ Male, $F=$ Female), Handedness $(R=R i g h t ; L=L e f t, A m b i .=$ Ambidexterous), the Time from Guanfacine Injection to the First Scan (In Minute = min), and the Effects of Guanfacine on Blood Pressure (BP; in Torr) are Given Below. . ${ }^{*}=$ Significant Overall by ANOVA or Sign Rank Test of Means ( $\left.p<.01\right)$, Due to Mean Lower Age of Normal Control Group than Control others, without Differences in Ranges Between Epilepsy Groups)

\begin{tabular}{|c|c|c|c|c|c|c|}
\hline Variable Group & Handedness & Sex & Age* & $\begin{array}{c}\text { Time to First } \\
\text { Postdrug Scan (Min.) }\end{array}$ & $\begin{array}{c}\text { BP Change, } \\
\text { Systolic }\end{array}$ & $\begin{array}{c}\text { BPChange, } \\
\text { Diastolic }\end{array}$ \\
\hline Normal Controls & $9 \mathrm{R}, 4 \mathrm{~L}$ & $8 \mathrm{M}, 5 \mathrm{~F}$ & $34 \pm 8(20-59)$ & $114 \pm 12$ & $-5 \pm 12$ & $+2 \pm 2$ \\
\hline Rest Controls & $5 \mathrm{R}, 1 \mathrm{~L}$ & $4 \mathrm{M}, 2 \mathrm{~F}$ & $46 \pm 9(35-58)$ & $110 \pm 11$ & $+3 \pm 9$ & $+4 \pm 8$ \\
\hline TLE & $10 \mathrm{R}, 2$ & $11 \mathrm{M}, 2 \mathrm{~F}$ & $39 \pm 11(24-48)$ & $105 \pm 10$ & $-5 \pm 14$ & $+6 \pm 10$ \\
\hline FLE & 9 R, 2 L, 1 ambi. & $9 \mathrm{M}, 3 \mathrm{~F}$ & $41 \pm 10(20-59)$ & $105 \pm 15$ & $+2 \pm 11$ & $+7 \pm 10$ \\
\hline
\end{tabular}

TLE $=$ temporal lobe epilepsy; FLE $=$ frontal lobe epilepsy.

p.o., is determined by analysis of a pilot study looking at the effects of guanfacine on working memory in similar subjects (Swartz et al. 1997). It corresponds to a dose range of $29-37 \mu \mathrm{g} / \mathrm{Kg}$, similar to that used in Jakala et al (1999). In that study, this dose produced a subjective sense of drowsiness but no performance decline. The scan data are not analyzed blindly as the statistical program is without subjective influence.

\section{Statistical Analysis}

All analyses were performed in statistical parametric mapping (SPM; Friston et al. 1989, 1990, 1991a, 1991b, 1994) using Pro-MatLab (The Mathworks). In SPM, the data are smoothed using a Gaussian filter to reduce error variance due to image noise and small-scale differences in functional and gyral anatomy. Prior to statistical computations, all images of CBF are scaled to an overall grand mean of $50 \mathrm{ml} 100 \mathrm{~g}^{-1} \mathrm{~min}^{-1}$. The procedure of proportional scaling is used to obtain the relative $\mathrm{CBF}$ and reduce the confounding effects of global changes in CBF. We analyzed each group separately, with the design being multiple subjects, two conditions with repetitions. The SPM program performs a voxelby-voxel t-test and generates a map showing the significance of any blood flow changes that are the main effect of conditions, covariates or groups and of interactions between those variables. The criteria for a significant effect are the magnitude of activity at each voxel, and the size of an area of increased activity (number of contiguous voxels with a t greater than the selected cutoff; Friston et al. 1994). A correction for multiple comparisons with respect to the number of voxels and number of hypotheses is automatically made. Regions found by ex- ploratory analyses are reported after correction, but in order to avoid a beta type statistical error, we are also reporting the uncorrected $p$ values at $p<.05$ for those regions included in our a priori hypotheses. Because only one-tailed t-tests are used, potential increases and decreases were tested separately. In this case the increases or decreases following guanfacine were relative to the control condition with no drug present, independent of task. We analyzed each group separately using the design of multiple subjects, two conditions, each with repetitions. We did not compare across groups so any global or regional difference in $\mathrm{rCBF}$ between groups is not a confounding variable.

\section{RESULTS}

\section{Subjects}

There are no significant differences in the sex ratios or handedness of the subject groups or in changes in blood pressure before and after guanfacine. An ANOVA of age vs. group is significant overall $(p=.01)$, due to the fact that the normal control group is somewhat younger than the other groups $(p=.05)$. There are no differences between the FLE, TLE and Rest control ages (Table 2a). In the FLE group, six of 11 subjects took diphenylhydantoin, nine of 11 took carbamazepine and other drugs were used in combination with these nine times. In the TLE group, five of twelve were taking diphenylhydantoin, ten of twelve were taking carbamazepine, and other drugs were used in combination with these seven times. There were no differences in the median doses of carbamazepine or diphenylhydantoin between these two groups (Table $2 b$ ).

Table 2b. Anticonvulsant Drugs (ACD) Used Across Groups. The Number of Subjects Taking Carbamazepine (CBZ) or Diphenylhydantoin (DPH), as Well as the Mean and Median Daily Dosage in mg is Given. There Were No Significant Differences Between Groups (Wilson Sign Rank Test). The Number of Other ACD's Used is also Indicated

\begin{tabular}{lcccccccc}
\hline & \multicolumn{3}{c}{ CBZ } & & \multicolumn{3}{c}{ DPH } \\
\cline { 2 - 3 } & Number & Mean Dose & Median Dose & & Number & Mean Dose & Median Dose & Other ACD's \\
\hline FLE & 9 of 11 & 900 & 800 & & 6 of 11 & 450 & 400 \\
TLE & 10 of 12 & 1180 & 1200 & & 5 of 12 & 350 & 300 & 7 \\
\hline
\end{tabular}


Table 3. Regions of Significant Change in rCBF Seen in the Control Groups. For This and Subsequent Figures, Smoothness FWHM $(\mathrm{mm})=18 \times 20 \times 16.4$., Height Threshold $=2.33, p=.01$; all Voxels Corrected for Multiple Comparisons Except Those Corresponding to the a priori Hypotheses (Uncorrected $p^{\prime}$ s in Parentheses). Bold Italics Represents Most Active Voxel in the Cluster; Non-Italics Indicates Voxels Within the Same Cluster

\begin{tabular}{|c|c|c|c|c|}
\hline \multicolumn{5}{|c|}{ a. Areas of Increased rCBF Following Guanfacine } \\
\hline Region & $\begin{array}{l}\text { Cluster } \\
\text { Level, } p\end{array}$ & $\begin{array}{l}\text { Voxels/ } \\
\text { Cluster }\end{array}$ & $\begin{array}{l}\text { Maximal Voxel } \\
\text { Level, } p\end{array}$ & $\begin{array}{c}\text { Stereotactic Coordinates } \\
\text { (Talairach and Tournoux, 1988) }\end{array}$ \\
\hline \multicolumn{5}{|l|}{ Normal controls } \\
\hline L sup. frontal g (Area 6) & .000 & 26,870 & .001 & $-10,-14,52$ \\
\hline L medial frontal g. (Area 6) & & & .002 & $-2,-18,56$ \\
\hline L precentral g. (Area 6) & & & .005 & $-34,-10,52$ \\
\hline \multicolumn{5}{|l|}{ Rest Controls } \\
\hline Central (Areas, 4, 1-3), $\mathrm{R}>\mathrm{L}$ & .392 & 816 & .035 & $40,-44,52$ \\
\hline \multicolumn{5}{|c|}{ b. Areas of Decreased rCBF Following Guanfacine } \\
\hline Region & $\begin{array}{c}\text { Cluster } \\
\text { Level, } \\
p\end{array}$ & $\begin{array}{l}\text { Voxels/ } \\
\text { Cluster }\end{array}$ & $\begin{array}{c}\text { Maximal Voxel } \\
\text { Level, } \\
p\end{array}$ & Coordinates \\
\hline \multicolumn{5}{|l|}{ Normal Controls } \\
\hline L mid-temporal gyrus (Area 21) & .04 & 2,261 & .02 & $-68,-56,4$ \\
\hline L occipital lobe (Area 19) & & & .03 & $-44,-56,4$ \\
\hline L inf. Parietal lobule (Area 40) & & & .10 & $-66,-44,34$ \\
\hline \multicolumn{5}{|l|}{ Rest Controls } \\
\hline L occipital lobe (Area 18) & .000 & 21,647 & .000 & $-44,-70,-18$ \\
\hline L inferior temporal g (Area 20) & & & .001 & $-50,-38,-26$ \\
\hline R occipital g (Area 18) & & & .002 & $40,-70,18$ \\
\hline
\end{tabular}

$\mathrm{L}=$ left; $\mathrm{R}=$ right; sup. = superior; inf = inferior; $\mathrm{g}=$ gyrus, Area - refers to Brodmann's areas (Brodmann 1909).

\section{Effects of Guanfacine on rCBF in Normal Controls}

Eight normal controls completed the study. Guanfacine produces both significant increases and decreases in $\mathrm{rCBF}$. The increases in $\mathrm{rCBF}$ are seen in a widespread distribution over both frontal and parietal cortices but are particularly prominent at the pre-motor area, extending from the superior frontal gyrus to the mid-frontal gyrus and pre-central gyrus (Table 3a; Figure 1). The mean increase in rCBF at the first voxel is $2.5 \mathrm{ml} 100 \mathrm{~g}^{-1}$ $\min ^{-1}(5 \%)$.

Figures 1-3 are SPM analyses superimposed onto an MRI template cut in three planes. On these color figures the color scale indicates increasing $\mathrm{Z}$ values from black to white. Figure 4 shows data in black and white through a "glass brain" in three planes. For all figures the resolution after smoothing at $16 \mathrm{~mm}$ was $18 \times 19 \times$ $17 \mathrm{~mm}$ full-width-half-maximum (FWHM). For all images, left side is up on the transverse images and to the left side of the coronal images.

Decreases are more prominent in both posterior hemispheres as well as the right perisylvian area. The significant areas of decrease are centered on the left mid-temporal gyrus (area 21) extending to the occipital cortex (area 19) and inferior parietal cortex (area 40). On the right side, decreases are noted in the posterior temporal cortex as well at the transverse temporal gyrus (area 41) extending to the mid-temporal gyrus (area 21) and anteriorly to the right posterior frontal operculum and insula (Table 3b; Fig 4a). The mean decrease in $\mathrm{rCBF}$ at the first voxel is $2 \mathrm{ml} 100 \mathrm{~g}^{-1} \mathrm{~min}^{-1}(4 \%)$.

\section{Effects of Guanfacine in "Rest Control" Group}

This group also shows significant decreases in $\mathrm{rCBF}$ in the occipital-temporal region. Significant increases are not seen, although a central parietal region approaches significance (Tables $3 a$ and $3 b$; Figure $4 b$ ).

\section{Effects in the Temporal Lobe Epilepsy (TLE) Group}

We studied nine subjects with TLE. In this group a somewhat different pattern is observed than in the controls. A large region of increased $\mathrm{rCBF}$ is noted over the frontal and central regions, as in the controls, but is most significant on the right from the mid-frontal gyrus (area 6) to the superior frontal gyrus (areas 6 and 8; Table 4a; Figure 2). (Recall that the epileptogenic or dysfunctional zones are on the left). The mean increase in rCBF at the first voxel is $3.5 \mathrm{ml} 100 \mathrm{ml}^{-1} \mathrm{~min}^{-1}$ or $7 \%$.

Wide areas of decrease in $\mathrm{rCBF}$ are again seen in the posterior hemispheres. These are maximal in the left cerebellar cortex and vermis, but, as in controls, extend to the left mid-temporal gyrus (area 37). A small area of decrease seen in the left inferior frontal gyrus did not reach statistical significance $(Z=3.9$; Table $4 b$; Fig $4 c)$. The mean decrease in $\mathrm{rCBF}$ at this voxel is $3.0 \mathrm{ml}$ $100 \mathrm{mg}^{-1} \mathrm{~min}^{-1}$ or $6 \%$. 


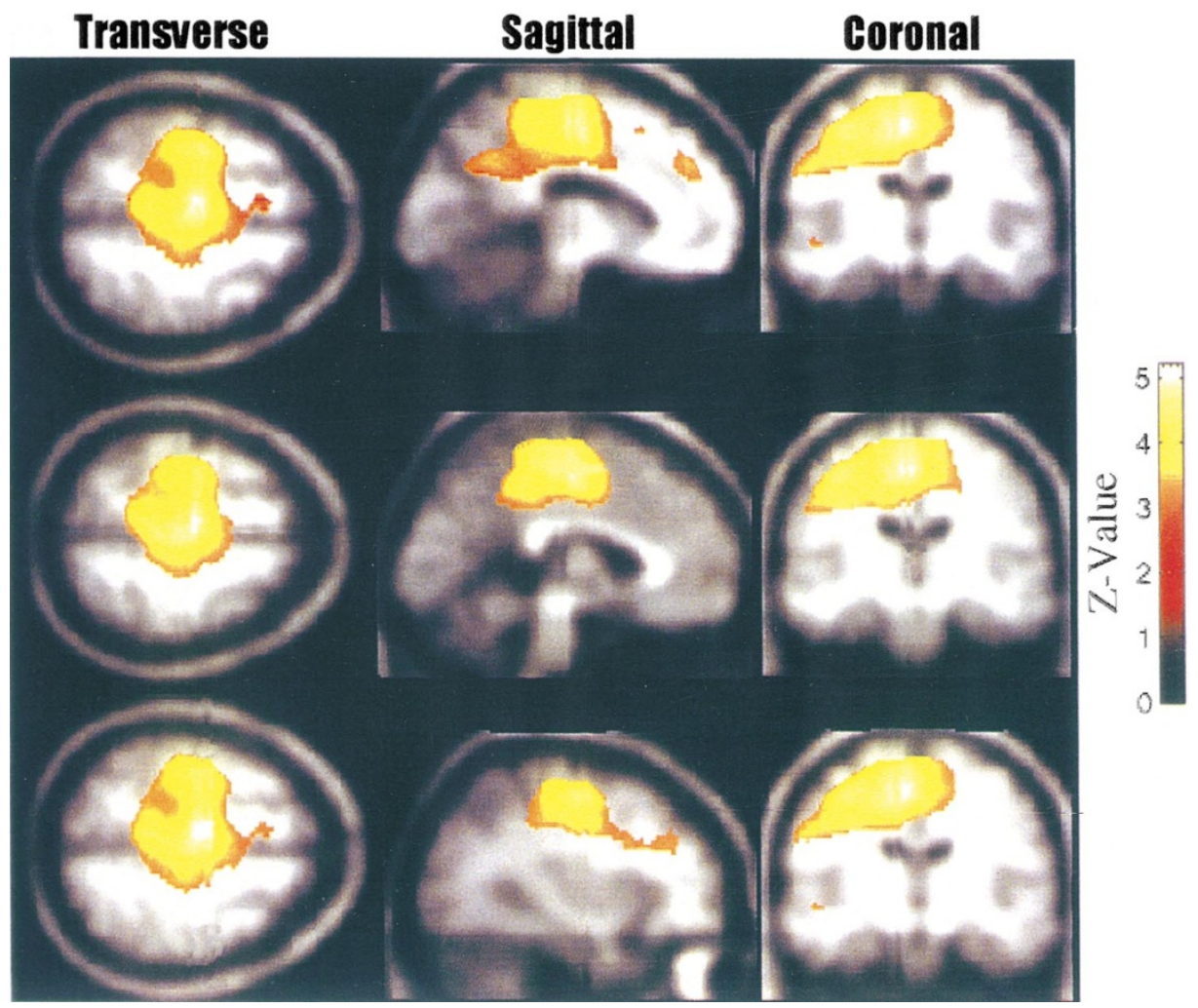

Figure 1. The regions of increase in $\mathrm{rCBF}$ following guanfacine $(p<.01$, corrected) in normal controls are shown in three planes, with three different sagittal cuts. A large area of activation is seen over the frontal and central cortex bilaterally, with maximal change on the left. See Table 3a for description of regions.

\section{Effects of Guanfacine in the Frontal Lobe Epilepsy Group}

This group, which consisted of 11 subjects with frontal lobe seizures, does not resemble controls or the TLE group. Increased rCBF is seen in bilateral temporal regions and the cingulate gyrus, anterior greater than posterior. The maximal significance is noted at the right mid-temporal gyrus, extending to the insula, and at the

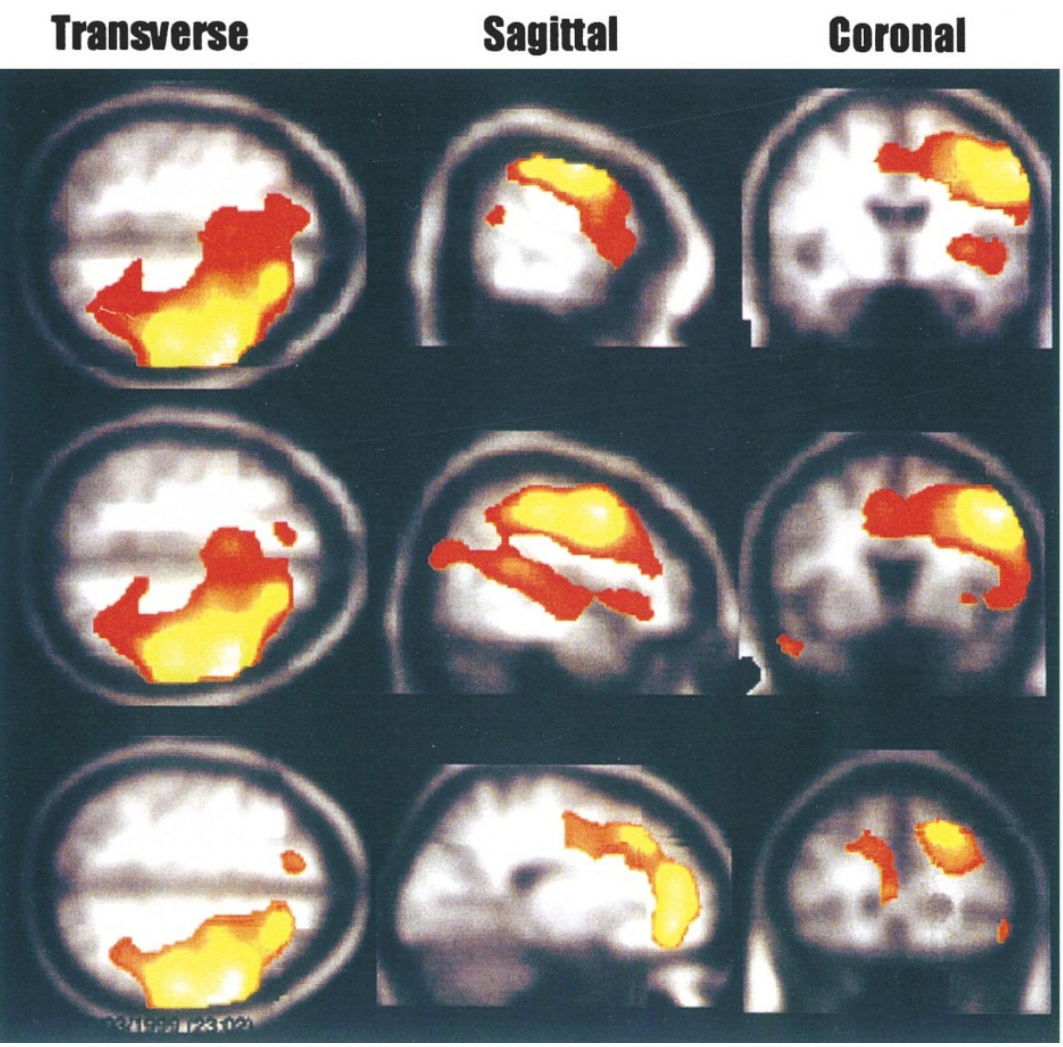

Figure 2. The regions of increase in $\mathrm{rCBF}$ following guanfacine in subjects with temporal lobe epi$\sum_{1}^{5}{ }^{4}{ }^{4}{ }^{4}$ lepsy (all foci on right) are shown $(p<.01$, corrected). Regions significantly increased at $p<.01$, uncorrected, are shown. A large area of activation is again seen in the frontal lobe but now is exclusively on the right, and extends further posteriorly. See Table $4 \mathrm{a}$ for a description of regions. 
Table 4. Regions of Significant Change in rCBF Seen in the TLE Group. All Parameters As in Table 3

\begin{tabular}{lcccc}
\hline & \multicolumn{2}{c}{ a. Regions with Increased rCBF Following Guanfacine } & \\
\hline Region & Cluster Level $(p)$ & Voxels/Cluster & Voxel Level $(p)$ & Coordinates \\
\hline R middle frontal g (Area 6) & .000 & 52,098 & .000 & $48,6,46$ \\
R superor frontal g (Area 6) & & & .000 & .000 \\
R superior frontal g (Area 8) & & & $22,-12,38,28,42$ \\
\hline & b. Regions with Decreased rCBF Following Guanfacine & & \\
\hline Region & Cluster level $(p)$ & Voxels/cluster & Voxel level $(p)$ & Coordinates \\
\hline L sup. Cerebellum & .000 & 14,596 & .000 & $-31,-71,-24$ \\
L cerebellar vermis & & & .001 & $-10,-64,-24$ \\
L middle temporal g. (Area 21) & & & .000 & $-52,-46,-26$ \\
\hline
\end{tabular}

right cingulate (area 24/32; Figure 3; Table 5a). The mean increase at the mid-temporal voxel is $3.5 \mathrm{mg}$ $100 \mathrm{ml}^{-1} \mathrm{~min}^{-1}$ or $7 \%$. This group does not show widespread posterior decreases as are seen in the control and TLE groups but does show a region of decreased rCBF in the left prefrontal cortex (area 10/46 to 9; Figure $4 \mathrm{~d}$; Table $5 \mathrm{~b}$ ). The mean decrease at the left PFC is $2.2 \mathrm{mg} 100 \mathrm{ml}^{-1} \mathrm{~min}^{-1}$ or $4.4 \%$.

\section{Task}

Across all groups there is a significant drug effect on the DMS task ( $p=.006$, Wilcoxon Signed Rank Test) with fewer errors post $(13 \pm 1.2 \%)$ than pre $(16 \pm 1.4 \%$, s.d.). This is not found on the IMS task, where there are
$4.5 \%$ errors pre- and $4.6 \%$ post-guanfacine. Group effects are seen for the DMS task performance prior to guanfacine (ANOVA; $p=.0005, \mathrm{df}=4, \mathrm{f}=5.4$ ). After guanfacine the differences in groups are similar qualitatively, but greater quantitatively $(p<.0001$ overall), with post-hoc differences noted between Control vs. FLE $(p=.0002)$ and TLE vs. FLE $(p=.07)$. These data are the subject of a separate manuscript (in preparation).

\section{DISCUSSION}

Changes in cerebral blood flow or glucose uptake are generally related to changes in synaptic activity and the

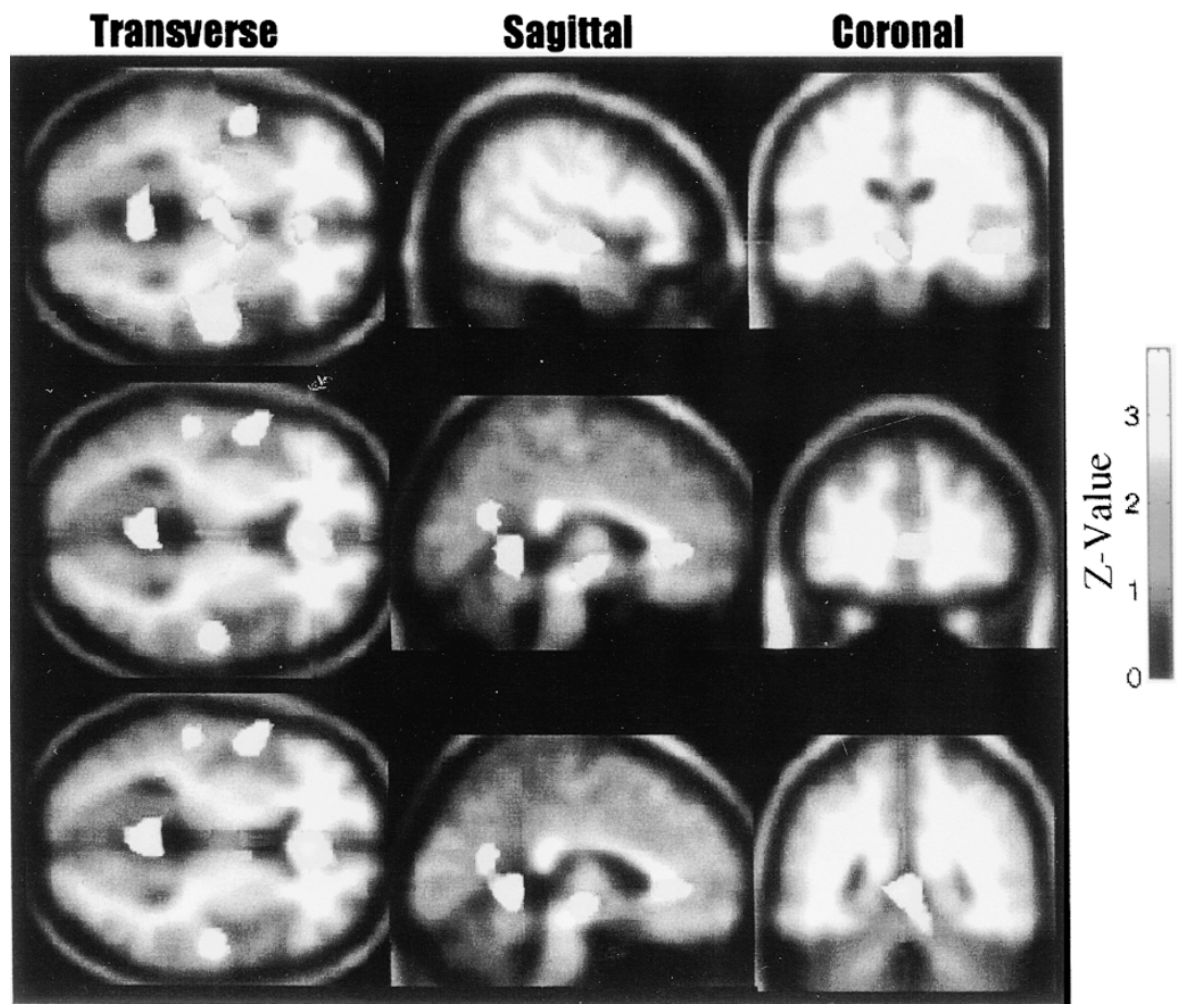

Figure 3. The regions of increase in $\mathrm{rCBF}$ following guanfacine in subjects with frontal lobe epilepsy (all foci on right) are shown $(p<.05$, uncorrected). No frontal regions show significant increases and only the right temporal region was significant at both the cluster and voxel levels (area and intensity). See Table 5 a for a description. 

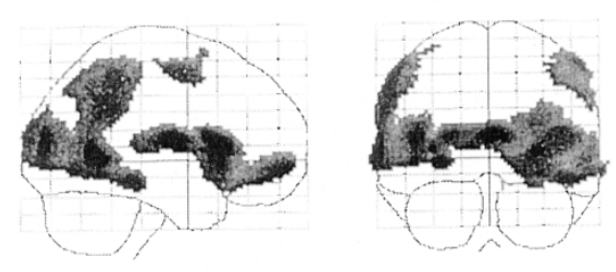

a.
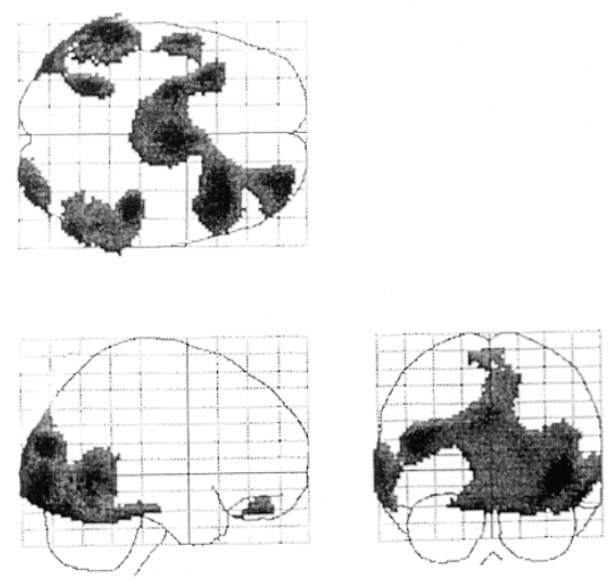

c.

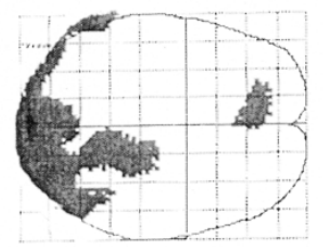

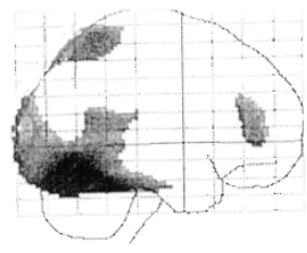

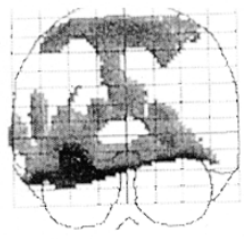

b.
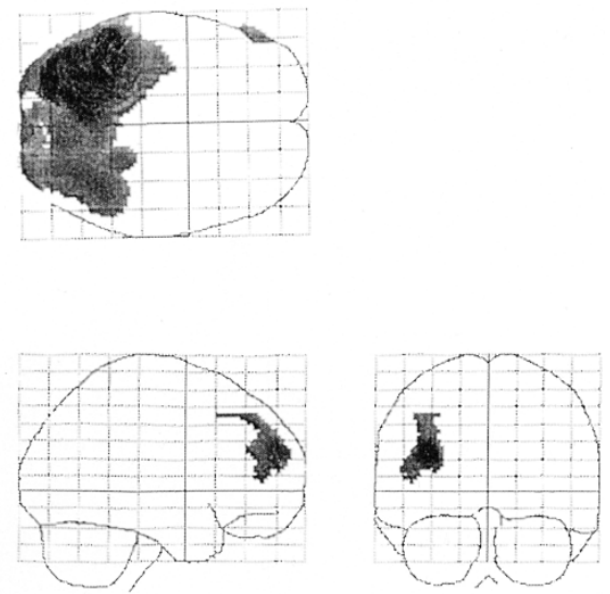

d.

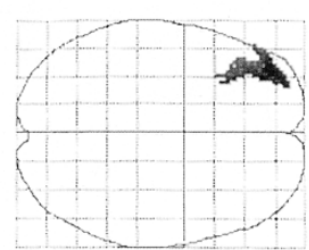

Figure 4. The regions of decreases in rCBF following guanfacine in are shown $(p<.05$, uncorrected). Panel (a) shows the normal control group. Panel (b) shows the resting control group. Both had maximal decreases in the occipital-temporal regions (See Table 3b). Panel (c) shows the decreases seen following guanfacine in the TLE group. These extend from the cerebellum to the mid-temporal gyrus. See Table $4 \mathrm{~b}$. Panel (d) The regions of decrease in rCBF following guanfacine in the FLE group are shown. Only an isolated area of the left frontal lobe was significant. See Table $5 b$ for explanation.

greatest metabolic demands are thought to occur at post-synaptic sites during generation of exhitatory and inhibitory post-synaptic potentials (EPSP's and IPSP's) (Sokoloff 1977; Kennedy et al. 1975; Jueptner and Weiller 1995). As mentioned, alpha-2 receptors can be pre- or post-synaptic, but the evidence suggests their actions in PFC be mediated through post-synaptic receptors. The norepinephrine fibers have a predominantly frontal distribution (Brown and Goldman 1977). In addition to classical synaptic structures, NE is released en passage from synaptic boutons directly to the extracellular space at axonal varicosities (Lapierre et al. 1973). This would be expected to produce widespread post-synaptic effects in the frontal lobes.

As hypothesized, our study finds increased cerebral blood flow in the frontal lobes of the normal control group. This is maximal in the central regions, consistent with the known distribution of catecholaminergic terminals in primates, and extends into the parietal re- gions. The smaller area of increased $\mathrm{rCBF}$ seen in the resting control group may be a beta type error, as larger groups are often necessary to observe stable effects in 15O-H2O rCBF studies (Andreason et al. 1996). The findings in this group, nevertheless, also agree with our hypothesis of anterior-increase and posterior-decrease in rCBF. Our subjects with temporal lobe epilepsy show frontal-parietal increases as well, although these increases are shifted to the side contralateral to the seizure focus, which may reflect an interaction of the temporal epileptogenic focus with the temporal-frontal connections that go from the middle temporal gyrus to the middle frontal gyrus (Barbas and Rempel-Clower 1997). These results agree with those produced by clonidine as reported by Moffoot et al. (1994) in Korsakoff's subjects, but differ from those reported by Coull and colleagues (1997) in controls treated with clonidine. This difference may be due to differing states of arousal at baseline or during tasks, or to differences in the dis- 
Table 5. Regions of Change in rCBF Seen in the FLE Group. All Parameters as in Table 3

\begin{tabular}{|c|c|c|c|c|}
\hline \multicolumn{5}{|c|}{ a. Regions Showing Increased rCBF Following Guanfacine } \\
\hline Region & Cluster level $(p)$ & Voxels/cluster & Voxel level $(p)$ & Coordinates \\
\hline R middle temporal g. (Area 42) & .05 & 1,439 & .02 & $50,-16,-2$ \\
\hline R superor temporal g. (Area 10) & & & .07 & $40,-24,-4$ \\
\hline R Insula & & & .08 & $34,6,-10$ \\
\hline $\mathrm{R}$ anterior cingulate & .31 & 650 & $.05(.000)$ & $2,34,4$ \\
\hline L sup. temporal g. (Area 42) & .39 & 629 & .05 & $-50,-6,4$ \\
\hline \multicolumn{5}{|c|}{ b. Regions Showing Decreased rCBF Followng Guanfacine } \\
\hline Region & Cluster level $(p)$ & Voxels/cluster & Voxel level $(p)$ & Coordinates \\
\hline L. middle frontal g. (Area 20) & .01 & 514 & .002 & $-36,-58,24$ \\
\hline L middle frontal g. (Area 10/46) & & & .06 & $-46,58,24$ \\
\hline L middle frontal g. (Area 9) & & & .09 & $-40,44,40$ \\
\hline
\end{tabular}

tribution of alpha-2A receptors, which guanfacine preferentially activates, and the alpha- $2 \mathrm{~B}, \mathrm{C}$ receptors which are additionally activated by clonidine.

We find decreases in $\mathrm{rCBF}$, which would be expected with a presynaptic alpha-2 effect in the posterior hemispheres of controls and subjects with TLE. These extended into the posterior temporal gyri, and inferior parietal lobe. This observation could explain why alpha-2 agonists may produce no change or worsening of performance on tests which tap perirhinal, hippocampal and parietal functions (Arnsten et al. 1998; Witte and Marrocco 1997). This distribution of change (increases anteriorly and decreases posteriorly) parallels that noted in a preliminary investigation of the effects of the D2 agonist, bromocriptine (Zarahn et al. 1998), Coull and colleagues (1997) also noted cerebellar and temporal-occipital decreases in $\mathrm{rCBF}$ following clonidine.

The subjects with frontal lobe epilepsy show a great deal of difference from controls or subjects with TLE. As predicted, they do not have increased rCBF ipsilateral to the epileptogenic zones. In fact the ipsilateral prefrontal cortex showed a decrease in rCBF. Catecholaminergic neurons are known to sprout into areas of neuronal loss, and an increase in presynaptic alpha-2 receptors in the PFC would explain our finding. Lesions within the frontal lobe might also disrupt any adrenergic cortico-cortical fibers passing posteriorly, explaining the lack of change in the central and parietal regions.

While the mechanisms supporting these changes are admittedly speculative, we can conclusively state that effects consistent with action at alpha-2 post-synaptic receptors are more prominent frontally in normal controls and subjects without known frontal dysfunction. Effects suggesting a pre-synaptic site of action are more prominent posteriorly. Our subjects with frontal lesions show significant reorganization. The contralateral, as well as ipsilateral, frontal depression in this group is not surprising as we have reported that prefrontal cortex contralateral and ipsolateral to epileptogenic re- gions fails to activate during a test of visual working memory, although it is structurally intact (Swartz et al. 1996a). Contrariwise, we saw an area of increase in rCBF following guanfacine in the right mid- and superior temporal gyri and adjacent insula of the FLE group. We have previously noted that disruption of higher cognitive prefrontal areas appears to result in reliance on limbic and temporal cortex for working memory tasks (Swartz et al. 1996b). The redistribution of alpha-2 receptors may be one mechanism subserving this functional shift. Previous studies have shown that the effects of alpha- 2 agonists on memory tasks or rCBF are specific to the agonist subclass, the task paradigm and the state of arousal. The markedly different response of the FLE group shows that the nature and location of neuropathology is also an important variable.

Our results cannot be explained by age differences for, while the temporal lobe group is like the control group in rCBF effects, it is like the frontal group in age distribution. Neither are they explained by anticonvulsant effects because each group is compared to itself, because anticonvulsants generally produce decreases in rCBF and because the type of drugs used do not significantly differ between the FLE and TLE groups (Theodore et al. 1986a, 1986b, 1989). Studies of intraventricular alpha-2 agonists have shown that they can produce local vasoconstriction or a global decrease in CBF due to effects at the brainstem control centers (Tsukahara et al. 1986; McPherson et al. 1997). We do not believe that changes in global cerebral blood flow affected the results because all groups are normalized to the same mean initially, because there are no significant changes in peripheral blood pressure, and because local changes in activity induced by an experimental condition are similar, whatever the background level of perfusion (Frackowiak and Friston 1994). Clearly, global decreases in CBF do not explain the increases in $\mathrm{rCBF}$ that we observed. Finally, we recognize that there is some heterogeneity of the location of the epileptic focus in the 
FLE and TLE groups. However, heterogeneity is expected to decrease statistical power, not increase it.

\section{CONCLUSIONS}

Alpha-2 agonists produce large increases in the cerebral blood flow of the dorsal prefrontal to central cortex, extending into parietal lobe, as predicted by the distribution of pre-synaptic adrenergic terminals reported in primates, and consistent with the enhancing effects previously noted in working memory paradigms. Decreases in the posterior temporal regions may relate to the lack of enhancement or impairing effect of alpha-2 agonists on temporal lobe tasks. Focal dysfunction, such as that produced by epilepsy, can alter this distribution both by direct effects at the epileptogenic site, as in the FLE group, and by indirect effects, as seen in the TLE group.

This study, as well as the other investigations cited herein, should encourage further attempts to characterize the effects of alpha-2 receptor sub-populations for potential therapeutic applications in a wide range of diseases with prefrontal dysfunction.

\section{ACKNOWLEDGMENTS}

The authors gratefully acknowledge the editorial assistance of Amy Arnsten, PhD, and the technical expertise of Charles Brown, MD, and the clinical expertise of A.V.Delgado-Escueta, $\mathrm{MD}$ and Gregory $\mathrm{O}$ Walsh, MD. This reserach was funded by the Veteran's Administration Research Service.

\section{REFERENCES}

Andreason NC, Arnot S, Cizadlo T, O’Leary P, Watkins G, Boles Porto L, Hichwa R (1996): Sample size and statistical power in [15O] $\mathrm{H} 2 \mathrm{O}$ studies of human cognition. J Cerebral Blood Flow Metabolism 16:804-816

Arnsten AF, Goldman-Rakic PS (1985): Alpha-2 adrenergic mechanisms in prefrontal cortex associated with cognitive decline in aged non-human primates. Science 230:1273-1276

Arnsten AF, Steere JC, Hunt RD (1996): The contribution of alpha-2-noradrenergic mechanism of prefrontal cortical cognitive functioning. Potential significance for attention-deficit-hypersensitivity disorder. Arch Gen Psychiatry 53:448-455

Arnsten AF, Steere JC, Teutsch DJ, Li BM (1998): Nonadrenergic influences on pre-frontal cortical cognitive function opposing actions at postjunctional alpha 1 versus alpha 2 receptors. Adv Pharmacol 42:764-767.

Arnsten AFT (1998): Catecholamine modulation of prefrontal cortical cognitive function. Trends in Cognitive Sci 2(11):436-446

Arnsten AFT, Cai JX, Goldman-Rakic PS (1988): The alpha-2 adrenergic agonist guanfacine improves memory in aged monkeys without sedative or hypotensive side effects: evidence for alpha-2 receptor subtypes. J Neuroscience 8(11):4287-4298

Arnsten AFT, Goldman-Rakic PS (1990): Analysis of alpha-2 adrenergic agonist effects on the delayed nonmatch-tosample performance of aged rhesus monkeys. Neurobiol Aging 11:583-590

Barbas H, Rempel-Clower N (1997): Cortical structure predicts the pattern of cortico-cortical connections. Cerebral Cortex 7:635-646

Bartus RT, Fleming D, Johnson HR (1978): Aging in the rhesus monkey: debilitating effects on short-term memory. J Gerontology 33:858-871

Brodmann K (1909): Vergleichende lokalisationlehre der gosshirnrinde. Leipzig, Barth

Brown RM, Goldman PS (1977): Catecholamines in the neocortex of rhesus monkeys: regional distribution and ontogenetic development. Br Res 124:576-580

Brozoski T, Brown RM, Rosvold HE, Goldman PS (1979): Cognitive deficit caused by regional depletion of dopamine in prefrontal cortex of rhesus monkey. Science 205:929-931

Cai OX, Ma YY, Xu L, Hu XT (1993): Reserpine impairs spatial working memory performance in monkeys: reversal by the alpha-2 agonist clonidine. Br. Res.; 614(1-2):191196

Carli M, Robbins TW, Evenden JL, Everit BJ (1983): Effects of lesions to ascending nonadrenergic neurons on performance of a 5-choice serial reaction task in rats: implications for theories of dorsal noradrenergic bundle function based on selective attention and arousal. Behav Br Res 9:361-380

Chappell PB, Riddle MA, Scahill L, Lynch KA, Schultz R, Arnsten A, Leckman JF, Cohen DJ (1995): Guanfacine treatment of comorbid attention deficit hyperactivity disorder and Tourette's Syndrome: preliminary clinical experience. J. Am Acad Child Adolesc Psychiatry 34:1140-1146

Coull JT, Frith CD, Dolan RJ, Frackowiak RS, Grasby PM (1997): The neural correlates of noradrenergic modulation of human attention, arousal and learning. Eur J Neurosci 9(3):589-598

Daniel DG, Weinberger DR, Jones DW, Zigun Jr (1991): The effect of amphetamine on regional cerebral blood flow during cognitive activation in schizophrenia. J. Neurosci 11(7):1907-1917

Delgado-Escueta AV, Walsh GO (1985): Type I complex partial seizures of hippocampal origin: excellent results of anterior temporal lobectomy. Neurology 35:143-154

Fields RB, Van Kammen DP, Peters JL, Roen J, Van Kammen WB, Nugent A, Stipetic M, Linnoila M (1988): Clonidine improves memory function in schizophrenia independently from change in psychosis. Schizophr Res 1:417-423

Frackowiak RSJ, Friston KJ (1994): Functional neuroanatomy of the human brain: positron emission tomography-a new neuroanatomical technique. J Anat 184:211-223

Franowicz JCS, Arnsten AFT (1998): The alpha-2A noradrenergic agonist, guanfacine, improves delayed response performance in young adult rhesus monkeys. Psychopharmacology 136:8-14 
Friston, KJ, Frith, CD, Liddle PF, Dolan, RJ, Lammertsma, AA, Frackowiak, RSJ (1990): The relationship between global and local changes in PET scans. J Cereb Blood Flow Metab 10:458-466

Friston, KJ, Frith CD, Liddle PF, Frackowiak RSJ (1991b): Comparing functional (PET) images: the assessment of significant change. J Cerebral Blood Flow Metab 11:690699

Friston KJ, Frith CD, Liddle PF, Lammertsma AA, Dolan RJ, Frackowiak RSJ (1991a): Plastic transformation of PET images. J Comput Assist Tomogr 15:634-639

Friston KJ, Passingham RE, Nutt JG, Heather JD, Sawle GV, Frackowiak RSJ (1989): Localization in PET images: Direct fitting of the intercommissural (AC-PC) line. J Cereb Blood Flow Metab 9:690-695

Friston KJ, Worsley KJ, Frackowiak RSJ, Mazziotta JC, Evans AC (1994): Assessing the significance of focal activations using their spatial extent. Human Brain Mapping $1: 210-220$

Goldman S, Rosvold HE (1979): Localization of function within the dorsolateral prefrontal cortex of the rhesus monkey. J Comp Neurol 171:369-386

Goldman-Rakic PS, Lidow MS, Gallagher DW (1990): Overlap of dopaminergic, adrenergic, and serotonergic receptors and complementarity of their subtypes in primates prefrontal cortex. J Neurosci 10:2125-2138

Harrison JK, Pearson WR, Lynch K (1991): Molecular characterization of alpha-1 and alpha-2-adrenergic receptors. Trends Pharmacol Sci 12:62-67

Horrigan JP, Barnhill LJ (1995): Guanfacine for treatment of attention-deficit disorder in boys. J Child Adolesc Psychopharmacol 5:215-223

Hunt RD, Mindera RB, Cohen DJ (1985): Clonidine benefits children with attention deficit disorder and hyperactivity: report of double-blind placebo-crossover therapeutic trial. J Am Acad Child Psychiatry 24:617-629

Hunt RD, Arnsten AFT, Asbell MD (1995): An open trial of guanfacine in the treatment of attention deficit hyperactivity disorder. J Am Acad Child Adolesc Psychiatry 34:50-54

Jackson W, Buccafusco IJ (1991): Clonidine enhances delayed match-to-sample performance by young and aged monkeys. Pharmacol Biochem Behav 39:79-84

Jakala P, Sirvio J, Riekkinen M, Koivisto E, Kejonen K, Vanhanen M, Riekkinen P (1999): Guanfacine and clonidine, alpha-2 agonists, improve paired associates learning, but not delayed matching to sample, in humans. Neuropsychopharmacology 20(2):119-130

Jueptner M, Weiller C (1995): Review: does measurement of regional cerebral blood flow reflect synaptic activity? Neuroimage 2:148-156

Kennedy C, des Rosiers M, Reivich M, Sharp F, Tehle JW, Sokoloff L (1975): Mapping of functional neural pathways by autoradiographic survey of local metabolic rate with [14C]-deoxyglucose. Science 187:850-853

Langer SZ (1974): Presynaptic receptors and their role in the regulation of transmitter release. B. J Pharmacol 60:481497

Lapierre Y, Beaudet A, Demianczuk N, Descarries L (1973): Noradrenergic axon terminals in the cerebral cortex. II
Quantitative data revealed by light and electron microscopic radioautography of the frontal cortex. Brain Res 63:175-182

Leslie FM, Laughlin SE, Steinberg DB, McGaugh JJ, Young LE (1985): Nonadrenergic changes and memory loss in aged mice. Br Res 359:292-299

Lewis DA, Campbell MJ, Foote SL, Goldstein M, Morrison JH (1987): The distribution of tyrosine hydrozylaseimmunoreactive fibers in primate neocortex is widespread but regionally specific. J Neurosci 7(1):279-290

Lewis DA, Campbell MJ, Foote SL, Morrison JH (1986): The monoaminergic innervation of primate neocortex. Human Neurobiol 5:181-188

Li BM, Kubota K (1998): Alpha-2-adrenergic modulation of prefrontal cortical neuronal activity related to a visual discrimination task with Go and No-Go performances in monkeys. Neurosci Res 31(2):83-95

Li BM, Mei ZT (1994): Delayed response deficit induced by local injection of the alpha-2-antagonist, yohimbine into the DLPFC in young adult monkeys. Behavior and Neurol Biol 62(2):134-139

Lidow MS, Goldman-Rakic PS, Gallager DW, Geschwind DH, Rakic P (1989): Distribution of major neurotransmitter receptors in the primary motor and somatosensory cortex of the rhesus monkey. Neurosci 32:609-627

Mair RG, McEntee WJ (1986): Cognitive enhancement in Korsakoff 's psychosis by clonidine: a comparison with L-dopa and ephedrine. Psychopharmacology (Berlin) 88:375-380

McEntee WJ, Mair RB (1980): Memory enhancement in Korsakoff's psychosis by clonidine: further evidence for a noradrenergic deficit. Neurology 1:466-470

McGaugh JJ, Liang KC, Bennet C, Steinberg DP (1984): Adrenergic influence on memory storage: interaction of peripheral and central systems. In Lynch G, McGaugh JJ, Weinberger NM (eds), Neurobiology of Learning and Memory. New York, Guildford, pp 313-332

McGaugh JL, Introini-Collison LB, Nagahara AH (1988): Memory-enhancing effects of post-training naloxone: involvement of beta-noradrenergic influences in the amygdaloid complex. Brain Res. 446(1):37-49

McPherson RW, Koehler RC, Kirsch JR, Traystman RJ (1997): Intraventricular dexmedetomidine decreases cerebral blood flow during normoxia and hypoxia in dogs. Anesth Analg 84:139-147

Moffoot A, O'Carroll RE, Murray C, Dougall N, Ebmeier K, Goodwin GM (1994): Clonidine infusion increases uptake of Tc-exametazamine in anterior cingulate cortex in Korsakoff's psychosis. Psycholog Med 24:53-61

Morrison JH, Molliner ME, Grzanna R (1979): Nonadrenergic innervation of cerebral cortex: widespread effects of local cortical lesions. Science 205:313-316

Oke AF, Adams RN (1978): Selective attention dysfunction in adult rats neonatally treated with 6-hydroxydopamine. Pharmacol Biochem Behav 9:429-432

Sawaguchi T. (1998): Attenuation of delay-period activity of monkey prefrontal neurons by an alpha-2-adrenergic antagonist during an oculomotor delayed-response task. J Neurophysiol 80(4):2200-2205

Sokoloff L (1977): Relation between physiological function 
and energy metabolism in the CNS. J Neurochem 29:1326

Steere JC, Arnsten AFT (1997): The alpha-2a noradrenergic agonist, guanfacine, improves visual object discrimination reversal performance in rhesus monkeys. Behav Neurosci 111:1-9

Stein L, Bellazzi JD, Wise CD (1975): Memory enhancement by central administration of norepinephrine. Br Res 84:329-335

Swartz BE, Delgado-Escueta AV (1987): Complex partial seizures of extratemporal origin: the evidence for. In Wiese HGr, Speckmann EJ, Engel J, (eds), Current Problems in Epilepsy. London, Paris, John Libbey, pp 137-144

Swartz BE, Delgado-Escueta AV, Zolo P (1991): Ictal electrographic onsets in frontal vs. temporal lobe epilepsy. Can J Neurological Sciences 18:649-662

Swartz BE, Halgren E, Simpkins F, Fuster J, Mandelkern M, Krisdakumtorn T, Brown C, Ropchan J, Blahd WH (1996a): Primary or working memory in frontal lobe epilepsy: An ${ }^{18}$ FDG-PET study of dysfunctional zones. Neurology 46(3):737-747

Swartz BE, Halgren E, Simpkins F, Mandelkern M (1996b): Studies of working memory using ${ }^{18}$ FDG-positron emission tomography in normal controls and subjects with epilepsy. Life Sciences 58(22):2057-2064

Swartz BE, Mandelkern A, Torgersen D, Thomas K (1997): Neuromodulatory agents, working memory and focal epilepsy. Epilepsia 88(S3):136

Swartz BE, Halgren E, Simpkins F, Syndulko K (1994): Primary memory in patients with frontal and primary generalized epilepsy. J Epilepsy 7(3):232-241

Swartz BE, Halgren E, Foster JM, Simpkins F, Gee M, Mandelkern M (1995): Cortical metabolic activation in humans during a visual memory task. Cerebral Cortex 3:205-214

Swartz BE, Delgado-Escueta AV, Walsh GO, Rich JR, DeSalles A, Kauffman M (1998): Surgical outcomes in pure frontal epilepsies and foci that mimic them. Epilepsy Research 29:97
Tanilla H, Rama P, Carlson S (1996): The effects of prefrontal intracortical microinjections of an alpha-2-agonist, alpha2 antagonist and lidocaine on the delayed-alternating performance of aged rats. Br Re Bull 40(2):117-119

Theodore WH, Bairamian D, Newmark ME, DiChiro G, Porter RJ, Larson S, Fishbein D (1986a): The effect of phenytoin on human cerebral glucose metabolism. J Cerebral Blood Flow Metab 6(3):315-320

Theodore WH, Bromfield E, Onerati L (1989): The effect of carbamazepine on CMRGlc. Ann Neurol 25:516-520

Theodore WH, DiChiro G, Margolin R, Fishbein D, Porter RJ, Brooks RA (1986b): Barbiturates reduce human CMRGlc. Neurology 36:60-64

Thomas MF, Moody TP, Makhinson M, O'Dell TJ (1996): Activity dependent beta-adrenergic modulation of low frequency induced LTP in the hippocampal CA1 region. Neuron 17(3):475-482

Tsukahara T, Taniguchi T, Usui H, Miwa S, Shimohama S, Fujiwara M, Handa H (1986): Sympathetic denervation and alpha adrenoreceptors in dog cerebral arteries. Naunyn Schmiedeberg's Arch Pharmacol 334:436-443

Walsh GO, Delgado-Escueta AV (1984): Type II complex partial seizures: poor results of anterior temporal lobectomy. Neurology 34:1-13

Witte EA and Marrocco RT (1997): Alterations of brain noradrenergic activity in rhesus monkeys affecting the alerting component of covert orienting. Psychopharmacology 132:315-323

Woods R, Cherry SR, Mazziotta JC (1992): Rapid automated algorithm for aligning and reslicing PET images. J Comp Assist Tomogr 16:620-633

Zarahn E., D'Esposito MD, Aguirre GK, Armstrong M, Lease J, Kimberg DY (1998): Cortical effects of bromocriptine, a D2-dopamine receptor agonist, on working memory and prefrontal function revealed by fMRI. So Neurosciences 24:1251 